\title{
Open vs. endovascular repair of abdominal aortic aneurysm: a comparative analysis
}

\author{
Análise comparativa entre tratamentos convencional e endovascular \\ de aneurisma de aorta abdominal \\ Samuel de Paula Miranda', Paschoal Cunha Miranda'1, Marília Granzotto Volpato', Maria Cláudia Folino', \\ Antônio Massamitsu Kambara', Fábio Henrique Rossi', Nilo Mitsuru Izukawa
}

\begin{abstract}
Context: Abdominal aortic aneurysm (AAA) is a condition that is usually asymptomatic, but potentially fatal, and has a prevalence in men over 60 years old ranging from $4.3 \%$ to $8 \%$. There are two treatment options available: open surgery (OS) and endovascular treatment (ET). Objective: To compare the results of repairs conducted using these two treatment methods from 2008 to 2013 in a tertiary hospital. Methods: A retrospective analysis comparing 119 patients treated with OS and 219 patients who underwent ET for AAA repair. Results: The ET group was older (71.3 vs. 68.2 years; $p<0.001$ ) and had a higher rate of coronary disease ( $44.7 \%$ vs. $27.7 \% ; p=0.002$ ) and a lower ejection fraction (57.6\% vs. 64.3\%; $\mathrm{p}<0.001)$; in turn, the OS group had more chronic obstructive pulmonary disease $(16.0 \%$ vs. 5.9\%; $p=0.004)$ and a smaller proximal infrarenal neck $(15.5 \mathrm{~mm}$ vs. $23.0 \mathrm{~mm} ; \mathrm{p}<0.001)$. However, there was no difference in ASA classification (American Society of Anesthesiology) ( $p=0.36$ ). The ET group had less intraoperative bleeding ( $171 \mathrm{~mL}$ vs. $729 \mathrm{~mL} ; \mathrm{p}<0.001$ ) and required fewer blood transfusions (11.9\% vs. 73.1\% $\mathrm{p}<0.001$ ), and spent shorter stays in both ICU (2.4 vs. 3.5 days; $p=0.002$ ) and hospital ( 5.8 vs. 10.3 days; $p<0.001)$. Thirty-day mortality was similar (OS 5.0\% vs. ET 4.1\%; $\mathrm{p}=0.78$ ) and there was also no difference in postoperative complications. The average cost of ET was higher ( $R \$ 34,277.76$ vs. $R \$ 4,778.60 ; p<0.001)$. Conclusions: Rates of morbidity and mortality were similar, although ET was associated with less bleeding, fewer transfusions and shorter hospital stays, but was more expensive.
\end{abstract}

Keywords: abdominal aortic aneurysm; vascular surgical procedures; endovascular procedures.

\begin{abstract}
Resumo
Contexto: $O$ aneurisma de aorta abdominal (AAA) é uma condição frequentemente assintomática, porém potencialmente fatal, cuja prevalência em homens com 60 anos ou mais está entre 4,3\% e 8\%. Existem duas modalidades de tratamento disponíveis: cirurgia aberta (TA) e endovascular (TE). Objetivo: Comparar os resultados dessas duas modalidades de tratamento, entre 2008 e 2013, em um hospital terciário. Métodos: Análise retrospectiva comparando 119 pacientes submetidos ao TA e 219 pacientes submetidos ao TE, para correção de AAA. Resultados: $\bigcirc$ grupo submetido ao TE apresentou maior idade (71,3 vs. 68,2 anos; $p<0,001$ ) e doença coronariana (44,7\% vs. 27,7\%; $p=0,002$ ), além de menor fração de ejeção (57,6\% vs. 64,3\%; p<0,001); por sua vez, o grupo submetido ao TA exibiu mais doença pulmonar obstrutiva crônica ( $16,0 \%$ vs. 5,9\%; $p=0,004)$ e menor colo proximal infrarrenal (15,5 mm vs. 23,0 mm; $p<0,001)$. Entretanto, não houve diferença na classificação ASA (American Society of Anesthesiology) $(p=0,36) .0$ grupo de TE apresentou menor sangramento intraoperatório (171 mL vs. 729 mL; $p<0,001$ ), com menor necessidade de hemotransfusão (11,9\% vs. 73,1\% p<0,001), menor permanência em UTI (2,4 vs. 3,5 dias; $p=0,002)$ e menor tempo de internação hospitalar (5,8 vs. 10,3 dias; $p<0,001$ ). A mortalidade em 30 dias foi semelhante (TA 5,0\% vs. TE 4,1\%; $p=0,78$ ), também não havendo diferença nas complicações pós-operatórias. O custo médio do TE foi maior (R\$34.277,76 vs. $R \$ 4.778,60 ; p<0,001)$. Conclusão: As taxas de morbimortalidade foram semelhantes, sendo no TE o sangramento, a necessidade transfusional e a duração da internação hospitalar menores, porém com custo mais elevado.
\end{abstract}

Palavras-chave: aneurisma de aorta abdominal; procedimentos cirúrgicos vasculares; procedimentos endovasculares. 


\section{INTRODUCTION}

Abdominal aortic aneurysm (AAA) is a condition that is usually asymptomatic and is potentially fatal by the time the first symptoms emerge. It is defined as dilation of the aorta greater than or equal to $3.0 \mathrm{~cm}$, which normally corresponds to more than two standard deviations above the mean diameter for men and women, or one and a half times larger than the individual's expected normal infrarenal diameter. ${ }^{1}$

Abdominal aortic aneurysms are generally diagnosed during routine examinations and, while they can cause abdominal or lumbar pains, rupture may be the first symptom. The risk of rupture is low when aneurysms are smaller than $5.5 \mathrm{~cm}$, but, when it does take place, just $25 \%$ of patients arrive at hospital alive and $10 \%$ survive surgery. ${ }^{2}$

More than 40 thousand procedures to repair AAA are performed every year in the United States. ${ }^{3}$ In São Paulo, Brazil, it is estimated that 1.8 to $3 \%$ of people over the age of 50 have the condition. ${ }^{2}$ Prevalence ranges from 4.3 to $8 \%$ in the subset of men aged 60 or over. ${ }^{4}$ Both prevalence and rupture rates are higher when there is a family history and/ or congenital diseases associated with the condition, such as Marfan and Ehler-Danlos syndromes. ${ }^{5}$

Elective surgical treatment is indicated for patients with aneurysms with diameters greater than $5.5 \mathrm{~cm}^{6}$ or with smaller diameters but other characteristics, such as female sex, presence of symptoms (pain and atheroembolism) and specific anatomic characteristics of the aneurysm (sacculations and ulcerations). ${ }^{3-5}$

In series of patients operated on at services with a great deal of experience, perioperative mortality rates ( $<30$ days) for treatment with open surgery (OS) range from 1.6 to $6.5 \%$, which is to a great extent the result of good operative management and to improvements in postoperative care. ${ }^{7,8}$

In 1991, Parodi et al. ${ }^{9}$ published an article on endovascular treatment (ET) for AAA that heralded a paradigm shift in the treatment of this disease. Since then, prospective, randomized and multicenter studies have demonstrated that perioperative morbidity and mortality are lower for ET when compared to OS. ${ }^{2-4}$

According to recently-published data, there is evidence to indicate that high risk patients benefit from ET, whereas the results are similar for both techniques in low risk patients with anatomy that is favorable for ET. The healthier subset of patients exhibited greater benefit from ET than from OS in terms of early mortality (30 days), but this did not translate into superior long-term survival. ${ }^{10,11}$
There are currently serious concerns about ET with relation to its durability, the rate of mediumterm complications, the need for reinterventions and the costs involved, and these issues have grown in importance to the extent that, with effective early screening, more and more young patients with high life expectancies are identified as candidates for AAA repair. ${ }^{7}$ However, as endoprostheses have been improved and experience with endovascular treatments has been acquired, these concerns appear to have been overestimated and not to reflect the true future scenario. ${ }^{12}$

Notwithstanding, OS to place prostheses under direct view has proven durable in two ways: firstly, the technique has been employed for more than 50 years and, secondly, the rate of complications related to prosthesis failure is around $0.3 \%$ per year. However, OS repair is major surgery, with morbidity and mortality rates that cannot be ignored.

In view of the heterogeneous nature of the profiles of patients who are candidates for treatment using the two different methods, in terms of clinical and anatomic conditions, it is very difficult to conduct robust randomization in order to conduct a comparative analysis of the two techniques. ${ }^{6,7}$ Very few studies with this design have been published and there is still no consensus on the ideal treatment. ${ }^{1,6,13-15}$

It is important to analyze local patient samples, given the complexity of the variables involved in selection of patients for each type of treatment and the technical and structural factors that can have an impact on the results. To date, no large-scale comparative studies have been conducted here in Brazil.

\section{OBJECTIVES}

The objective of this study was to compare the results of open surgery and endovascular treatment of patients with abdominal aortic aneurysms treated from 2008 to 2013 at a tertiary hospital, by means of a retrospective analysis based on systematic review of medical records.

\section{METHOD}

A retrospective, single-center, observational and cross-sectional analysis was conducted by reviewing the medical records for 119 patients who were treated with open surgery (OS) and 219 patients who underwent endovascular treatment (ET) to repair an abdominal aortic aneurysm (AAA) from 2008 to 2013 at the Dante Pazzanese Cardiology Institute. 
Inclusion criteria were as follows: patients diagnosed with AAA with diameter $>5.0 \mathrm{~cm}$, seen on multidetector angiotomography, with a minimum postoperative follow-up of 30 days.

Patients were excluded from the sample if they had undergone emergency OS or ET for ruptured AAA, if they had aneurysms of the thoracoabdominal aorta, or if 30-days' postoperative follow-up was not available.

Demographic analysis covered the following patient data: age, sex, race, risk factors for AAA, diabetes mellitus, smoking, systemic arterial hypertension, dyslipidemia, carotid stenosis, coronary artery disease, chronic obstructive pulmonary disease and chronic renal failure. We also harvested data on body mass index, ejection fraction on echocardiogram and maximum aneurysm diameter.

The following characteristics of aneurysm repair were analyzed, type of anesthesia (general or general plus local), configuration of repair (straight or bifurcated prosthesis and type of endoprosthesis), in addition to perioperative data: duration of procedure, estimated blood loss, autologous and heterologous transfusions, mean intravenous contrast use and mean fluoroscopy duration.

The following postoperative complications were noted: mortality; acute myocardial infarction; stroke; acute renal failure; major amputation; mesenteric ischemia; hemorrhage; infection of the surgical wound; ischemia of lower limbs; venous thromboembolism; bronchopneumonia, and leakage from endoprostheses.

The mean lengths of stays in the intensive care unit and hospital were estimated, as were the costs of procedures.

Total cost of treatment was estimated by analyzing the fees paid by the Brazilian National Health Service (SUS - Sistema Único de Saúde) to the Dante Pazzanese Cardiology Institute, the cost of stays in conventional wards and the intensive care unit, the prices of bifurcated and straight Dacron prostheses, the price of units of blood products used and the autotransfusion equipment, and the total price of the procedure.

The variables of interest were input to a spreadsheet for statistical analysis using the R3.0.1 software program and results with $\mathrm{p}<0.05$ were considered significant.

Qualitative variables were analyzed using Fisher's two-tailed exact test, and quantitative variables were analyzed using the $t$ test or the Mann-Whitney test, depending on the distribution of the variable in question. Normality of distribution of quantitative variables was verified using the Shapiro-Wilk test .
The study was approved by the institutional Research Ethics Committee.

\section{RESULTS}

\section{Demographic characteristics of patients}

From January 2008 to March 2013, 338 patients underwent elective treatment of abdominal aortic aneurysms (AAA), 119 of whom were treated with open surgery (OS) and 219 received endovascular treatment (ET).

The group that received ET were older $(71.3$ vs. 68.2 years; $p<0.001)$ and had a higher rate of coronary disease $(44.7 \%$ vs. $27.7 \%$; $p=0.002)$, and a lower ejection fraction on echocardiogram $(57.6 \% \mathrm{vs}$. $64.3 \% ; \mathrm{p}<0.001)$; in turn, the OS group had a higher rate of COPD ( $16.0 \%$ vs. $5.9 \%$; $=, 004)$ and smaller proximal infrarenal necks $(15.5 \mathrm{~mm}$ vs. $23.0 \mathrm{~mm}$; $\mathrm{p}<0.001)$. However, there was no difference in ASA classification $(p=0.36)$. The OS group also had more complex anatomic characteristics, with a higher proportion of juxtarenal and pararenal aneurysms ( $11.3 \%$ vs. $4.1 \%$ and $4.8 \%$ vs. $0.45 \%$, respectively, $p<0.001)$. The remaining demographic characteristics and underlying clinical conditions are listed in Table 1.

\section{Treatment and postoperative data}

General anesthesia was used for almost all of the patients in the ET group (99.1\%), while general anesthesia combined with local blockade was administered to the majority of the OS group $(65.5 \%)$. Aorto-aortic grafts were used in $51.3 \%$ of the OS patients and a bifurcated endoprosthesis was fitted in $88.6 \%$ of the ET group. The characteristics of aneurysm repairs can be found in Table 2 .

When compared with open surgery, endovascular patients had shorter duration of procedure (105.9 vs. $235.0 \mathrm{~min} ; \mathrm{p}<0.001$ ), had less intraoperative bleeding (171 vs. $729.5 \mathrm{~mL} ; \mathrm{p}<0.001$ ) and needed fewer blood transfusions $(11.9 \%$, vs. $73.1 \% ; \mathrm{p}<0.001)$, spent less time in the ICU ( 2.4 vs. 3.5 days; $p<0.001)$ and had shorter hospital stays (5.8 vs. 10.3 days; $\mathrm{p}<0.001$ ). Table 3 lists the perioperative data.

The cost analysis showed that, on average, OS was significantly cheaper than ET (R $\$ 4,778.60$ vs. $\mathrm{R} \$ 34,277.76 ; \mathrm{p}<0.001)$. Tables 4 and 5 lists the costs of the procedures and blood products employed.

\section{Outcomes and adverse events}

Thirty-day mortality was similar (OS 5.0\% vs. ET $4.1 \% ; p=0.78)$ and there were no statistical differences in postoperative complications (Table 6) 
Table 1. Demographic characteristics of patients treated for AAA.

\begin{tabular}{|c|c|c|c|}
\hline Characteristic & OS Group ( $n=119)$ & ET Group $(n=219)$ & $\mathrm{p}$ \\
\hline Age (years) & $68.2 \pm 6.9$ & $71.3 \pm 9.0$ & $<0.001$ \\
\hline Male sex - No. (\%) & $89(74.8)$ & $183(83.6)$ & 0.06 \\
\hline Race - No. (\%) & & & 0.39 \\
\hline White & $107(88.9)$ & $203(92.7)$ & \\
\hline Black & $4(3.4)$ & $3(1.4)$ & \\
\hline Mixed & $8(6.7)$ & $13(5.9)$ & \\
\hline Hypertension - No. (\%) & $108(90.8)$ & $193(88.1)$ & 0.58 \\
\hline Diabetes mellitus - No. (\%) & $22(18.5)$ & $61(27.9)$ & 0.64 \\
\hline Dyslipidemia - No. (\%) & $73(61.3)$ & $139(63.5)$ & 0.72 \\
\hline Smoking - No. (\%) & $108(90.8)$ & $170(77.6)$ & 0.03 \\
\hline CRF - No. (\%) & $16(13.4)$ & $30(13.7)$ & 1.00 \\
\hline COPD - No. (\%) & $19(16.0)$ & $13(5.9)$ & 0.004 \\
\hline Carotid Disease - No. (\%) & $22(18.5)$ & $24(11.0)$ & 0.067 \\
\hline Coronary disease - No. (\%) & $33(27.7)$ & $98(44.7)$ & 0.002 \\
\hline BMI $\left(\mathrm{kg} / \mathrm{m}^{2}\right)$ & $25.7 \pm 4.3$ & $26.3 \pm 4.2$ & 0.41 \\
\hline $\mathrm{EF}(\%)$ & $64.3 \pm 8.3$ & $57.6 \pm 13.9$ & $<0.001$ \\
\hline ASA classification - No. (\%) & & & 0.36 \\
\hline 1 & $1(0.8)$ & $0(0)$ & \\
\hline II & $41(34.5)$ & $77(35.2)$ & \\
\hline III & $74(62.2)$ & $140(63.9)$ & \\
\hline IV & $3(2.5)$ & $2(0.9)$ & \\
\hline Maximum diameter of AAA $(\mathrm{cm})$ & $6.4 \pm 1.5$ & $6.2 \pm 1.1$ & 0.54 \\
\hline Proximal neck (mm) & $15.5 \pm 14.2$ & $23.0 \pm 10.2$ & $<0.001$ \\
\hline Type of Aneurysm - No. (\%) & & & 0.001 \\
\hline Infrarenal & $99(83.2)$ & $209(95.4)$ & \\
\hline Juxtarenal & $14(11.8)$ & $9(4.1)$ & \\
\hline Pararenal & $6(5.0)$ & $1(5.0)$ & \\
\hline Iliac aneurysm- No. (\%) & & & 0.34 \\
\hline Unilateral & $16(13.4)$ & $31(14.2)$ & \\
\hline Bilateral & $36(30.3)$ & $82(37.6)$ & \\
\hline Absent & $67(56.3)$ & $105(48.2)$ & \\
\hline
\end{tabular}

OS - open surgery; ET - endovascular treatment; CRF - chronic renal failure; COPD - chronic obstructive pulmonary disease; BMI - body mass index; EF - ejection fraction on echocardiogram; ASA - American Society of Anesthesiologists; AAA - abdominal aortic aneurysm.

\section{DISCUSSION}

The objective of treatment to repair AAA is to avert rupture and death. With the advent of ET, created by Parodi et al. ${ }^{9}$ in 1991, a new and less invasive option associated with fewer perioperative complications became available. ${ }^{11}$ Since then, new techniques, materials and endoprostheses have been developed and their therapeutic results analyzed.

We reviewed the literature, but found just four randomized studies that have compared the techniques ${ }^{6,11,15,16}$ and found no studies conducted in Brazil that had used this method of comparison. Those studies that do exist either compared specific outcomes (reintervention and renal failure rates) ${ }^{17-19}$ or studied restricted groups with specific characteristics (the elderly, obese patients and high surgical risk patients). , $^{3,20,21}$

The group of patients who underwent ET were older, had a higher proportion of coronary disease and a lower ejection fraction. The elevated prevalence of comorbidities is because our service is a national referral center for cardiovascular diseases. High risk patients are referred here for treatment and, in many cases, the endovascular option was chosen because it is less invasive, less time-consuming and requires shorter stays in both ICU and hospital. Other studies have reported similar results, corroborating the benefits of ET. , $11,22,23^{2}$

In selected groups of low to intermediate risk patients, there was no difference between OS and ET in terms of survival or major or minor complications. 
Table 2. Characteristics of aneurysm repair.

\begin{tabular}{|c|c|c|}
\hline Characteristic - Number of patients (\%) & OS Group $(n=119)$ & ET Group $(n=219)$ \\
\hline \multicolumn{3}{|l|}{ Type of Anesthesia } \\
\hline General & $41(34.5)$ & $217(99.1)$ \\
\hline General + Local & $78(65.5)$ & $2(0.9)$ \\
\hline \multicolumn{3}{|l|}{ Distal Anastomosis } \\
\hline Aorto-aortic & $61(51.3)$ & - \\
\hline Aortobiiliac & $48(40.3)$ & - \\
\hline Aortobifemoral & $07(5.9)$ & - \\
\hline Aortoiliac or aortofemoral & $03(2.5)$ & - \\
\hline \multicolumn{3}{|l|}{ Configuration of Prosthesis } \\
\hline Straight & $61(51.3)$ & - \\
\hline Bifurcated & $58(48.7)$ & - \\
\hline \multicolumn{3}{|l|}{ Configuration of Endoprosthesis } \\
\hline Straight & - & $25(11.4)$ \\
\hline Bifurcated & - & $194(88.6)$ \\
\hline Monoiliac & - & $0(0)$ \\
\hline \multicolumn{3}{|l|}{ Type de Endoprosthesis } \\
\hline Zenith (Cook) & - & $54(24.6)$ \\
\hline Talent (Medtronic) & - & $27(12.3)$ \\
\hline Endurant (Medtronic) & - & $35(15.9)$ \\
\hline Excluder (Gore) & - & $38(17.3)$ \\
\hline Powerlink (Endologix) & - & $34(15.5)$ \\
\hline Others ${ }^{*}$ & - & $31(14.1)$ \\
\hline
\end{tabular}

OS - open surgery; ET - endovascular treatment; *Other endoprostheses used: Anaconda (19), Aorfix (9), Apolo (3).

Table 3. Perioperative data.

\begin{tabular}{lccc}
\hline \multicolumn{1}{c}{ Variable } & OS Group $(\mathrm{n}=119)$ & ET Group $(\mathrm{n}=219)$ & $\mathrm{p}$ \\
\hline Mean duration $(\mathrm{min})$ & $235.0 \pm 62.8$ & $105.9 \pm 45.7$ & $<0.001$ \\
Blood loss $(\mathrm{mL})$ & $729.5 \pm 1038$ & $171.0 \pm 175.5$ & $<0.001$ \\
Blood transfusion needed - No. (\%) & $87(73.1)$ & $26(11.9)$ & $<0.001$ \\
Time clamped (min) & $60.8 \pm 23.8$ & - & \\
Volume of contrast $(\mathrm{mL})$ & - & $136.6 \pm 58.2$ & $22.9 \pm 15.9$ \\
Fluoroscopy duration $(\mathrm{min})$ & - & $2.4 \pm 5.0$ & 0.002 \\
Stay in ICU (days) & $3.5 \pm 8.4$ & $5.8 \pm 7.6$ & $<0.001$ \\
Stay in hospital (days) & $10.3 \pm 11.4$ & & \\
\hline
\end{tabular}

OS - open surgery; ET - endovascular treatment.

The choice of the best treatment method should depend on weighing up the different risks involved: while open surgery is associated with longer hospital stays, more transfusions during the postoperative period and complications related to the incision, the endovascular option demands more intensive follow-up using tomography and is associated with a higher reintervention rate and a small, but persistent, risk of rupture of the AAA. ${ }^{11}$ Treatment choices must therefore be individualized and the treating physician should take into account the patient's life expectancy, their surgical risk assessment, the anatomy of the aneurysm and also patient preference. ${ }^{10}$
In addition to infrarenal AAA patients, the sample analyzed here also included patients with juxtarenal and pararenal aneurysms. In these cases we adopted a cautious approach to indicating ET because of the greater likelihood of reintervention and renal failure in this group of patients, as reported in other published studies. ${ }^{6,15,21,24}$

With regard to the characteristics of the procedures conducted, the entire patient sample was given general anesthesia; and local anesthesia was also administered in $65.5 \%$ of cases in the OS group. This approach enables reduced infusion of anesthetic agents both during the procedure and 


\begin{tabular}{lc}
\hline & Mean cost in Brazilian Reais (R\$) $)^{1}$ \\
\hline Dacron Prosthesis & 550.00 \\
Straight & 690.00 \\
Bifurcated & \\
Endoprosthesis & $14,000.00$ \\
Main Body & $10,200.00$ \\
Extensions (individual) & \\
Open Aneurysmectomy of Abdominal Aorta & $1,240.7$ \\
Hospital Services & 371.72 \\
Professionals' Fees & $1,622.26$ \\
Total & \\
Endovascular repair of abdominal aortic aneurysm ${ }^{2}$ & $1,240.74$ \\
Hospital Services & 371.72 \\
Professionals' Fees & $1,622.26$ \\
Total & \\
Mean cost of hospital stay per 5 days in standard bed ${ }^{3}$ & 436.61 \\
Hospital Services & 72.08 \\
Professionals' Fees & 508.69 \\
Total & \\
Mean cost of hospital stay per 5 days in intensive care unit & \\
Hospital Services & \\
Professionals' Fees & 436.65 \\
\hline Total & 72.08 \\
\hline
\end{tabular}

${ }^{1}$ Sums paid by the Brazilian National Health Service (SUS - Sistema Único de Saúde), on average; ${ }^{2}$ Varies depending on the number of extensions employed; ${ }^{3}$ Up to 10 days, the price of two 5-day packages is charged, thereafter, from the 11th day onwards, R\$20 are added per additional day in hospital.

Table 5. Average Unit Costs for Blood Products (Red Blood Cell Concentrate and Fresh Frozen Plasma).

\begin{tabular}{lc}
\hline & Mean cost in Brazilian Reais (R\$) \\
\hline Immunohematology & 15.00 \\
Collection, per Bag & 22.00 \\
Screening & 10.00 \\
Serology, per Bag & 75.00 \\
Processing & 10.15 \\
Total & 132.15 \\
\hline *Sums paid by the Brazilian National Health Service (SUS - Sistema Único de \\
Saúde).
\end{tabular}

in the postoperative period; earlier extubation; better pain control and earlier return to walking; fewer pulmonary, thromboembolic and abdominal complications and even a lower rate of coronary events because of reduced sympathetic tone. In our opinion, this practice may be responsible for the low rate of postoperative complications observed in this study. While it is possible to conduct ET with local anesthesia alone, this is not routine conduct at our service. With the patient intubated, apnea can be applied, facilitating placement and more precise release of the endoprosthesis in patients with unfavorable proximal aortic necks, which is a common presentation among our patients. Our proportion is similar to the DREAM study, ${ }^{6}$ in which 94.7\% of the patients in an ET group were given general anesthesia.

With regard to the types of surgical distal anastomoses performed, the aorto-aortic type was most frequent $(51.3 \%)$, followed by aortobiiliac (40.3\%), also in common with the DREAM study ${ }^{6}$ (59.8\% and $33.3 \%$, respectively). The most common type of endoprosthesis used was the bifurcated $(88.6 \%)$, with a rate of $94 \%$ in the literature. ${ }^{6}$

While ET offers lower operative morbidity and shorter hospital stays, the literature shows that ET is more expensive than OS. In this study, ET had a mean cost $700 \%$ higher than the cost of OS (R $\$ 34,277.76$ vs. $\mathrm{R} \$ 4,778.60 ; \mathrm{p}<0.001)$. This cost difference is primarily caused by the prices of the endoprostheses, which has also been reported in other published studies. ${ }^{25-28}$ On average, the cost of the endoprosthesis accounts for $70 \%$ of the total cost of the procedure.

In the Brazilian literature there is only one study that has investigated this subject. It was published by Mendonça et al. ${ }^{7}$ in 2005 and assesses the costs for 31 patients treated with OS and 18 patients given ET $(n=49)$. The mean total cost of the procedure 
Table 6. Postoperative complications of open and endovascular treatment of AAA.

\begin{tabular}{|c|c|c|c|}
\hline Variable & OS Group $(n=119)$ & ET Group $(n=219)$ & $\mathrm{p}$ \\
\hline \multicolumn{4}{|l|}{ Major Complications- No. (\%) } \\
\hline Death & $6(5.0)$ & $9(4.1)$ & 0.78 \\
\hline Acute myocardial infarction & $1(0.8)$ & $8(3.7)$ & 0.17 \\
\hline Stroke & $2(1.7)$ & $0(0)$ & 0.12 \\
\hline Dialytic Acute Renal Failure & $6(5.0)$ & $6(2.7)$ & 0.36 \\
\hline Major Amputation & $2(1.7)$ & $0(0)$ & 0.12 \\
\hline Mesenteric Ischemia & $1(0.8)$ & $1(0.5)$ & 1.00 \\
\hline Major Hemorrhage & $3(2.5)$ & $6(2.8)$ & 1.00 \\
\hline \multicolumn{4}{|l|}{ Minor Complications- No. (\%) } \\
\hline Infection of Surgical Wound & $1(0.8)$ & $9(4.1)$ & 0.11 \\
\hline Ischemia of Lower Limbs & $13(10.9)$ & $33(15.1)$ & 0.32 \\
\hline Venous Thromboembolism & $0(0)$ & $0(0)$ & 0 \\
\hline Non-Dialytic Acute Renal Failure & $9(7.6)$ & $15(6.8)$ & 0.83 \\
\hline Bronchopneumonia & $9(7.6)$ & $9(4.1)$ & 0.21 \\
\hline Minor Hemorrhage & $5(4.2)$ & $13(5.9)$ & 0.62 \\
\hline \multicolumn{4}{|l|}{ Endoleaks - No. (\%) } \\
\hline Type I & - & $14(6.4)$ & \\
\hline Type II & - & $13(5.9)$ & \\
\hline Type III & - & $9(4.1)$ & \\
\hline Type IV & - & $3(1.4)$ & \\
\hline
\end{tabular}

OS - open surgery; ET - endovascular treatment.

was $456 \%$ more expensive in the ET group (cost of $\mathrm{ET}=\mathrm{R} \$ 48,063.00$, cost of $\mathrm{OS}=\mathrm{R} \$ 11,020.00)$. Once more, the primary factor responsible for this difference was the price of the endoprosthesis, which corresponded to $77.4 \%$ of the total cost. However, that study did not employ the fees paid by the SUS, but calculated costs for a group of patients who all had private health plans, with a total of 21 patients in the OS and 16 in the ET groups.?

Schermerhorn ML et al. conducted a retrospective study of data from patients who had been treated on an American healthcare system (Medicare) for AAA with endovascular or open surgery between 2001 and 2004, with follow-up to 2005. A total of 45,660 patients were analyzed, 22,830 patients in each group, with a mean age of 76 years. Perioperative mortality was lower in the endovascular group than in the open surgery group $(1.2 \%$ vs. $4.8 \%$; $<<0.001)$ and mean hospital stay was also shorter (3.4 vs. 9.3 days; $\mathrm{p}<0.001) .{ }^{29}$

In the present study, there were no statistically significant differences between the two techniques in terms of mortality or postoperative complications. The 30-day mortality rate for OS was $5.0 \%$, compared with $4.1 \%$ for ET. There are four largescale randomized controlled studies in the literature that have shown lower mortality postoperative mortality rates after ET (EVAR-1, ${ }^{30}$ DREAM, ${ }^{6}$
$\mathrm{ACE}^{31}$ and $\left.\mathrm{OVER}{ }^{15}\right)$. Mortality at 30 days or while in hospital after endovascular treatment was $2.1 \%$ in EVAR-1, 1.2\% in DREAM, $0.6 \%$ in ACE and $0.5 \%$ in OVER. For OS, mortality was $4.3 \%$ in EVAR-1, 4.6\% in DREAM, $1.3 \%$ in ACE and 3.0\% in OVER. However, publications giving long-term data from these studies did not report significant difference in long-term survival. ${ }^{16,32-35}$ Although the choice of treatment took into consideration clinical and anatomic characteristics, the fact that our sample was composed of a majority of patients with high surgical risk appears to have contributed to higher mortality rates than reported by the large-scale studies. The differences are greater for our ET group results, since patients were older and had higher rates of heart disease and coronary disease, which are important predictors of mortality in AAA treatment. 6,16,35,36

The higher number of patients with dialytic acute renal failure in the OS group is probably related to the higher prevalence, among our patients, of complex aneurysms, requiring clamping above the renal arteries or even reimplantation of the renal arteries. Notwithstanding, with the development of branched and fenestrated stents, in addition to new endovascular techniques, there is a trend for increased proportions of patients with unfavorable characteristics to be treated with ET; however, no comparative studies have been published to date. ${ }^{6,35,36}$ 
Although this study describes the largest sample of Brazilian patients studied to date, it suffers from the limitations of being neither randomized nor prospective and from a short postoperative followup (30 days). The groups were not uniform because the patients were chosen for one or another type of treatment on the basis of their clinical and anatomic features.

This five-year comparative analysis of two methods of treating AAA has shown that, despite similar rates of early complications, endovascular treatment is associated with shorter duration procedures, shorter hospital stays and a reduced need for transfusions in comparison with open surgery. While the cost involved remains high, there is a trend for the prices of endoprostheses to fall and endovascular treatment should be considered more and more often as a good option for management of AAA in patients treated by the SUS.

\section{REFERENCES}

1. Moll FL, Powell JT, Fraedrich G, et al. Management of abdominal aortic aneurysms clinical practice guidelines of the European society for vascular surgery. Eur J Vasc Endovasc Surg. 2011;41(41, 1):S1-58. http://dx.doi.org/10.1016/j.ejvs.2010.09.011. PMid:21215940

2. Puech-Leafio P, Molnar LJ, Oliveira IR, Cerri GG. Prevalence of abdominal aortic aneurysms: a screening program in Safio Paulo, Brazil. Sao Paulo Med. J. 2004;122(4):158-60.

3. Gupta PK, Ramanan B, Lynch TG, et al. Endovascular repair of abdominal aortic aneurysm does not improve early survival versus open repair in patients younger than 60 years. Eur J Vasc Endovasc Surg. 2012;43(5):506-12. http://dx.doi.org/10.1016/j. ejvs.2012.02.006. PMid:22386386

4. Greenhalgh RM, Powell JT. Endovascular repair of abdominal aortic aneurysm. N Engl J Med. 2008;358(5):494-501. http://dx.doi. org/10.1056/NEJMct0707524. PMid:18234753

5. Lederle FA. Abdominal aortic aneurysm-open versus endovascular repair. N Engl J Med. 2004;351(16):1677-9. http:// dx.doi.org/10.1056/NEJMe048258. PMid:15483287

6. Prinssen $M$, Verhoeven EL, Buth J, et al. A randomized trial comparing conventional and endovascular repair of abdominal aortic aneurysms. N Engl J Med. 2004;351(16):1607-18. http:// dx.doi.org/10.1056/NEJMoa042002. PMid:15483279

7. Mendonça CT, Moreira RCR, Timi JRR, et al. Comparação entre os tratamentos aberto e endovascular dos aneurismas de aorta abdominal em pacientes de alto risco cirúrgico. J Vasc Bras. 2005;4(3):232-42. http://dx.doi.org/10.1590/ S1677-54492005000300004.

8. Rossi FH. Pós-Operatório Hospitalar na Cirurgia Vascular e Endovascular. Condutas Terapêuticas do Instituto Dante Pazzanese de Cardiologia. Atheneu. 2006;1:6-6.

9. Parodi JC, Palmaz JC, Barone HD. Transfemoral intraluminal graft implantation for abdominal aortic aneurysms. Ann Vasc Surg. 1991;5(6):491-9. http://dx.doi.org/10.1007/BF02015271. PMid:1837729
10. Moulakakis KG, Dalainas I, Kakisis J, Mylonas S, Liapis CD. Endovascular Treatment versus Open Repair for Abdominal Aortic Aneurysms: The Influence of Fitness in Decision Making. Int J Angiol. 2013;22(1):9-12. http://dx.doi. org/10.1055/s-0033-1333868. PMid:24436578

11. Becquemin JP, Pillet JC, Lescalie F, et al. A randomized controlled trial of endovascular aneurysm repair versus open surgery for abdominal aortic aneurysms in low- to moderate-risk patients. J Vasc Surg. 2011;53(5):1167-1173.e1. http://dx.doi.org/10.1016/j. jvs.2010.10.124. PMid:21276681

12. Sandford RM, Choke E, Bown MJ, Sayers RD. What is the best option for elective repair of an abdominal aortic aneurysm in a young fit patient? Eur J Vasc Endovasc Surg. 2014;47(1):13-8. http://dx.doi.org/10.1016/j.ejvs.2013.09.014. PMid:24239144

13. United Kingdom EVAR Trial Investigators, Greenhalgh RM, Brown LC, Powell JT, Thompson SG, Epstein D. Endovascular repair of aortic aneurysm in patients physically ineligible for open repair. N Engl J Med. 2010;362(20):1872-80. http://dx.doi.org/10.1056/ NEJMoa0911056. PMid:20382982

14. Brown LC, Epstein D, Manca A, Beard JD, Powell JT, Greenhalgh RM. The UK Endovascular Aneurysm Repair (EVAR) trials: design, methodology and progress. Eur J Vasc Endovasc Surg. 2004;27(4):372-81. http://dx.doi.org/10.1016/j.ejvs.2003.12.019. PMid:15015186

15. Lederle FA, Freischlag JA, Kyriakides TC, et al. Outcomes following endovascular vs open repair of abdominal aortic aneurysm: a randomized trial. JAMA. 2009;302(14):1535-42. http://dx.doi. org/10.1001/jama.2009.1426.

16. United Kingdom EVAR Trial Investigators, Greenhalgh RM, Brown $\mathrm{LC}$, et al. Endovascular versus open repair of abdominal aortic aneurysm. N Engl J Med. 2010;362(20):1863-71. http://dx.doi. org/10.1056/NEJMoa0909305. PMid:20382983

17. Giles KA, Landon BE, Cotterill P, O'Malley AJ, Pomposelli FB, Schermerhorn ML. Thirty-day mortality and late survival with reinterventions and readmissions after open and endovascular aortic aneurysm repair in Medicare beneficiaries. J Vasc Surg. 2011;53(1):6-13.e1. http://dx.doi.org/10.1016/j.jvs.2010.08.051.

18. Qadura M, Pervaiz F, Harlock JA, et al. Mortality and reintervention following elective abdominal aortic aneurysm repair. J Vasc Surg. 2013;57(6):1676-83.e1. http://dx.doi.org/10.1016/j. jvs.2013.02.013. PMid:23719040

19. Antonello M, Menegolo M, Piazza M, Bonfante L, Grego F, Frigatti P. Outcomes of endovascular aneurysm repair on renal function compared with open repair. J Vasc Surg. 2013;58(4):886-93. http:// dx.doi.org/10.1016/j.jvs.2013.02.249.

20. Biancari F, Catania A, D'Andrea V. Elective endovascular vs. open repair for abdominal aortic aneurysm in patients aged 80 years and older: systematic review and meta-analysis. Eur J Vasc Endovasc Surg. 2011;42(5):571-6. http://dx.doi.org/10.1016/j. ejvs.2011.07.011. PMid:21820922

21. Raval MV, Eskandari MK. Outcomes of elective abdominal aortic aneurysm repair among the elderly: endovascular versus open repair. Surgery. 2012;151(2):245-60. http://dx.doi.org/10.1016/j. surg.2010.10.022. PMid:21244863

22. de la Motte L, Jensen LP, Vogt K, Kehlet H, Schroeder TV, Lonn L. Outcomes after elective aortic aneurysm repair: a nationwide Danish cohort study 2007-2010. Eur J Vasc Endovasc Surg. 2013;46(1):57-64. http://dx.doi.org/10.1016/j.ejvs.2013.04.020. PMid:23683392

23. Adriaensen ME, Bosch JL, Halpern EF, Myriam Hunink MG, Gazelle GS. Elective endovascular versus open surgical repair of abdominal aortic aneurysms: systematic reviewof short-term 
results. Radiology. 2002;224(3):739-47. http://dx.doi.org/10.1148/ radiol.2243011675. PMid:12202708

24. Carpenter JP, Baum RA, Barker CF, et al. Impact of exclusion criteria on patient selection for endovascular abdominal aortic aneurysm repair. J Vasc Surg. 2001;34(6):1050-4. http://dx.doi.org/10.1067/ mva.2001.120037. PMid:11743559

25. Min SI, Min SK, Ahn S, et al. Comparison of costs of endovascular repair versus open surgical repair for abdominal aortic aneurysm in Korea. J Korean Med Sci. 2012;27(4):416-22. http://dx.doi. org/10.3346/jkms.2012.27.4.416. PMid:22468106

26. Morimae H, Maekawa T, Tamai H, et al. Cost disparity between open repair and endovascular aneurysm repair for abdominal aortic aneurysm: a single-institute experience in Japan. Surg Today. 2012;42(2):121-6. http://dx.doi.org/10.1007/s00595-011-0041-4. PMid:22072152

27. Prinssen $M$, Buskens $E$, Jong $S E$, et al. Cost-effectiveness of conventional and endovascular repair of abdominal aorticaneurysms: results of a randomized trial. J Vasc Surg. 2007;46(5):883-90.e1. http://dx.doi.org/10.1016/j.jvs.2007.07.033. PMid:17980274

28. Stroupe KT, Lederle FA, Matsumura JS, et al. Cost-effectiveness of open versus endovascular repair of abdominal aortic aneurysm in the OVER trial. J Vasc Surg. 2012;56(4):901-9.e2. http://dx.doi. org/10.1016/j.jvs.2012.01.086. PMid:22640466

29. Schermerhorn ML, O'Malley AJ, Jhaveri A, Cotterill P, Pomposelli F, Landon BE. Endovascular vs. open repair of abdominal aortic aneurysms in the Medicare population. $\mathrm{N}$ Engl J Med. 2008;358(5):464-74. http://dx.doi.org/10.1056/NEJMoa0707348. PMid:18234751

30. EVAR trial participants. Endovascular aneurysm repair versus open repair in patients with abdominal aortic aneurysm (EVAR trial 1): randomised controlled trial. Lancet. 2005;365(9478):217986. http://dx.doi.org/10.1016/S0140-6736(05)66627-5. PMid:15978925

31. Becquemin JP. The ACE trial: a randomized comparison of open versus endovascular repair in good risk patients with abdominal aortic aneurysm. J Vasc Surg. 2009;50(1):222-4. http://dx.doi. org/10.1016/j.jvs.2009.04.074. PMid:19563976

32. Blankensteijn JD, Jong SE, Prinssen $M$, et al. Two-year outcomes after conventional or endovascular repair of abdominal aortic aneurysms. N Engl J Med. 2005;352(23):2398-405. http://dx.doi. org/10.1056/NEJMoa051255.

33. Schermerhorn ML, Finlayson SR, Fillinger MF, Buth J, van Marrewijk C, Cronenwett JL. Life expectancy after endovascular versus open abdominal aortic aneurysm repair: results of a decision analysis model on the basis of data from EUROSTAR. J Vasc Surg. 2002;36(6):1112-20. http://dx.doi.org/10.1067/ mva.2002.129646. PMid:12469041
34. De Bruin JL, Baas AF, Buth J, et al. Long-term outcome of open or endovascular repair of abdominal aortic aneurysm. N Engl J Med. 2010;362(20):1881-9. http://dx.doi.org/10.1056/NEJMoa0909499.

35. Chadi SA, Rowe BW, Vogt KN, et al. Trends in management of abdominal aortic aneurysms. J Vasc Surg. 2012;55(4):924-8. http:// dx.doi.org/10.1016/j.jvs.2011.10.094. PMid:22226189

36. Verhoeven EL, Prins TR, Tielliu IF, et al. Treatment of short-necked infrarenal aortic aneurysms with fenestrated stent-grafts: shortterm results. Eur J Vasc Endovasc Surg. 2004;27(5):477-83. http:// dx.doi.org/10.1016/j.ejvs.2003.09.007. PMid:15079769

Correspondence Samuel de Paula Mirand Av. Dante Pazzanese, 500, Ibirapuera CEP: 04012-909 - São Paulo (SP), Brazi E-mail: samueldepaula@gmail.com

Author information SPM - Resident physician, Centro de Intervenções Endovasculares (CIEV), Instituto Dante Pazzanese de Cardiologia. PCM - Resident physician, Centro de Intervenções Endovasculares (CIEV), Instituto Dante Pazzanese de Cardiologia. MGV - Resident physician, Centro de Intervenções Endovasculares (CIEV), Instituto Dante Pazzanese de Cardiologia. MCF - Resident physician, Centro de Intervenções Endovasculares

(CIEV), Instituto Dante Pazzanese de Cardiologia.

AMK - MSc in Medicine from Universidade Federal de São Paulo

(UNIFESP). Head, Radiology Section, Centro de Intervenções Endovasculares (CIEV), Instituto Dante Pazzanese de Cardiologia. Ful member, Colégio Brasileiro de Radiologia.

FHR - PhD in Medicine from Universidade de São Paulo (USP). Assistant physician, Vascular Surgery Section, Centro de Intervenções Endovasculares (CIEV), Instituto Dante Pazzanese de Cardiologia. NMI - PhD in Medicine from Universidade de São Paulo (USP), Head, Vascular Surgery Section, Centro de Intervenções Endovasculares (CIEV), Instituto Dante Pazzanese de Cardiologia.

Author contributions Conception and design: SPM, PCM, MGV, FHR Analysis and interpretation: SPM, PCM, MGV, FHR Data collection: SPM, PCM, MGV, MCF Writing the article: SPM, PCM, MGV, MCF Critical revision of the article: AMK, FHR, NM Final approval of the article*: SPM, FHR

Statistical analysis: SPM Overall responsibility: FHR, NM

*All authors have read and approved of the final version of the article submitted to I Vasc Bras. 